\title{
Statistical analysis of the correlation between the equatorial electrojet and the occurrence of the equatorial ionisation anomaly over the East African sector
}

\author{
Patrick Mungufeni $^{1}$, John Bosco Habarulema ${ }^{2,3}$, Yenca Migoya-Orué ${ }^{4}$, and Edward Jurua ${ }^{1}$ \\ ${ }^{1}$ Mbarara University of Science and Technology, P.O. Box 1410 Mbarara, Uganda \\ ${ }^{2}$ South African National Space Agency (SANSA) Space Science, Hermanus 7200, South Africa \\ ${ }^{3}$ Department of Physics and Electronics, Rhodes University, Grahamstown 6140, South Africa \\ ${ }^{4}$ T/ICT4D laboratory of the Abdus Salam International Center for Theoretical Physics, 34151 Trieste, Italy
}

Correspondence: Patrick Mungufeni (pmungufeni@gmail.com)

Received: 11 November 2017 - Revised: 8 May 2018 - Accepted: 23 May 2018 - Published: 13 June 2018

\begin{abstract}
This study presents statistical quantification of the correlation between the equatorial electrojet (EEJ) and the occurrence of the equatorial ionisation anomaly (EIA) over the East African sector. The data used were for quiet geomagnetic conditions $(\mathrm{Kp} \leq 3)$ during the period 2011-2013. The horizontal components, $H$, of geomagnetic fields measured by magnetometers located at Addis Ababa, Ethiopia (dip lat. $\sim 1^{\circ} \mathrm{N}$ ), and Adigrat, Ethiopia (dip lat. $\sim 6^{\circ} \mathrm{N}$ ), were used to determine the EEJ using differential techniques. The total electron content (TEC) derived from Global Navigation Satellite System (GNSS) signals using 19 receivers located along the $30-40^{\circ}$ longitude sector was used to determine the EIA strengths over the region. This was done by determining the ratio of TEC over the crest to that over the trough, denoted as the $\mathrm{CT}$ : TEC ratio. This technique necessitated characterisation of the morphology of the EIA over the region. We found that the trough lies slightly south of the magnetic equator $\left(0-4^{\circ} \mathrm{S}\right)$. This slight southward shift of the EIA trough might be due to the fact that over the East African region, the general centre of the EEJ is also shifted slightly south of the magnetic equator. For the first time over the East African sector, we determined a threshold daytime EEJ strength of $\sim 40 \mathrm{nT}$ that is mostly associated with prominent EIA occurrence during a high solar activity period. The study also revealed that there is a positive correlation between daytime EEJ and EIA strengths, with a strong positive correlation occurring during the period 13:00-15:00 LT.
\end{abstract}

Keywords. Ionosphere (equatorial ionosphere)

\section{Introduction}

One of the factors that determines the distribution of ambient ion and electron density in the low-latitude $\mathrm{F}$ region ionosphere is the vertical $\boldsymbol{E} \times \boldsymbol{B}$ drift, which is roughly directly proportional to the equatorial electrojet (EEJ) during daytime (Anderson et al., 2002). The daytime EEJ is a narrow band of enhanced eastward current flowing in the $100-120 \mathrm{~km}$ altitude region within $\pm 3^{\circ}$ latitude of the dip equator (Chapman, 1951; Rastogi, 1974). The horizontal configuration of the Earth's magnetic field at the dip equator leads to the inhibition of the Hall current. The resulting increase in Cowling conductivity produces the EEJ (Abdu, 1992; Hajra et al., 2009). The EEJ current reverses and flows in a westward direction in most cases during quiet geomagnetic and low solar activity conditions as well as during solstice months (Gouin and Mayaud, 1967; Reddy, 1989). This phenomenon is referred to as the counter electrojet (CEJ).

The upward $\boldsymbol{E} \times \boldsymbol{B}$ drift lifts plasma to higher altitudes, which then diffuses north and south along magnetic field lines. Due to gravity and pressure gradient forces, there is also a downward diffusion of plasma. The net effect is the formation of two belts of high electron density around magnetic latitudes of $\pm 15^{\circ}$. This phenomenon is known as the equatorial ionisation anomaly (EIA) (Appleton, 1946). The regions with high electron density are referred to as crests of the EIA, while the region over the magnetic equator with low electron density is called the trough of the EIA. The process that leads to the formation of the EIA is sometimes referred to as the fountain effect. 
The large enhancements in electron densities on either side of the magnetic equator significantly affect radio frequency signals passing through the ionosphere and groundto-ground high-frequency communication systems (Anderson et al., 2004). Due to such problems, several studies have been undertaken to understand the influence of the EEJ on the development of the EIA. Most of the studies related to the development of the EIA and EEJ have been done over American and Indian longitude sectors (Sethia et al., 1980; Chakraborty and Hajra, 2009; Hajra et al., 2009; Zhang et al., 2009; Yizengaw et al., 2010; Venkatesh et al., 2015; Rodriguez-Zuluaga et al., 2016). There are also some studies that have used global data to study the morphology of the EIA. For instance, Yue et al. (2015) derived peak electron density in the F2 layer ( $\mathrm{NmF} 2)$ from the Global Position System (GPS) Radio Occultation (RO) observations made by the Constellation Observation System for Meteorology, Ionosphere and Climate (COSMIC) mission to study the morphology of the EIA statistically during 2006-2014. They found that $N m \mathrm{~F} 2$ increases more significantly with solar activity in the crest region than that of the trough region. The ratio of $N m \mathrm{~F} 2$ at the crest to that at the trough has one peak in the noontime and another around the time of occurrence of the pre-reversal enhancement (PRE) of the zonal electric field. The ratios are smaller during May-August than other months for all the local times (LT). Rush and Richmond (1973) also used global data to investigate the relationship between the EIA and the strength of the EEJ. They found that the correlation coefficients between hourly parameters that define development of the EIA and the midday EEJ strength tend to maximise between 13:00 and 16:00 LT. On a seasonal basis, the correlation coefficients tend to minimise around the June solstice.

However, there are a few studies that have used data over the African region to examine occurrence of the EIA during geomagnetically disturbed (e.g. Yizengaw et al., 2010; Olwendo et al., 2015) and quiet conditions (Bolaji et al., 2017). The study by Bolaji et al. (2017) used data during quiet geomagnetic and low solar activity conditions in the year 2009 to confirm the roles of the EEJ and integrated EEJ (IEEJ) in determining the hemispheric extent of the EIA crest over African mid-latitudes and low latitudes. They reported that, in the Southern Hemisphere, EIA crests can be seen in the magnetic latitudes ranging from about 17 to $19^{\circ} \mathrm{S}$.

At the moment, there is no statistical quantification of the correlation between the EEJ strength and the formation/development of the EIA over the African sector. Therefore, this study focused on statistically quantifying the correlation between daytime EEJ strength and the occurrence of the EIA over the East African sector during the high solar activity years of 2011-2013. The method we used necessitated searching for locations of the trough and crest of the EIA over the region. The data that were used in this study are described in Sect. 2.

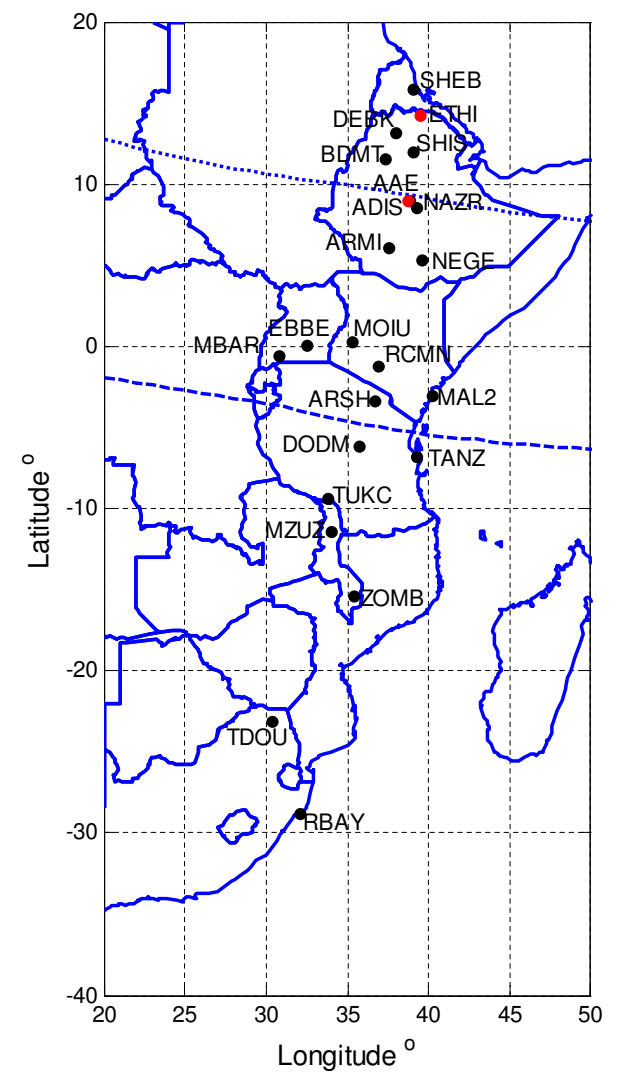

Figure 1. A map showing data sites. The red and black dots indicate the locations of the magnetometers and the UNAVCO stations, respectively. The dotted and dashed lines represent the magnetic equator and the southern crest of the EIA, respectively.

\section{Data and analyses}

\subsection{EEJ data}

The daytime strength of the EEJ can be determined by calculating the difference between the magnitudes of the horizontal component, $H$, of Earth's magnetic field measured by magnetometer placed directly on the magnetic equator and displaced $6-9^{\circ}$ away from the magnetic equator (Anderson et al., 2004). The locations of the magnetometers at Adigrat, Ethiopia (ETHI) (http://magnetometers.bc.edu, last access: 15 September 2017), and Addis Ababa, Ethiopia (AAE) (http://www.intermagnet.org, last access: 15 September 2015), that were used in this study to determine the daytime strengths of the EEJ are shown in Fig. 1 by red dots. The same magnetometers have been used in several studies to determine the EEJ over the East African sector (e.g. Yizengaw et al., 2014, 2010; Olwendo et al., 2015). In Fig. 1, the dotted line represents the magnetic equator, while the dashed line represents the southern crest of the EIA. More details about data sites used in this study are provided in Table 1. The last column of the table shows the usage of a data site, i.e. to 
Table 1. Sites of GNSS receivers and magnetometers used in the study.

\begin{tabular}{llrrrl}
\hline \multirow{2}{*}{ Station name, country } & Station code & \multicolumn{2}{c}{ Geog. coord. } & \multirow{2}{*}{ Mag. lat $\left(^{\circ}\right)$} & Purpose \\
\cline { 3 - 4 } & & Long $\left(^{\circ}\right)$ & Lat $\left(^{\circ}\right)$ & & \\
\hline Adigrat, Ethiopia & ETHI & 39.5 & 14.3 & 5.9 & EEJ \\
Addis Ababa, Ethiopia & AAE & 38.8 & 9.0 & 1.3 & EEJ \\
Sheba, Eritrea & SHEB & 39.1 & 15.9 & 7.6 & TEC \\
Debarek, Ethiopia & DEBK & 37.9 & 13.15 & 4.5 & TEC \\
Shimsheha, Ethiopia & SHIS & 39.0 & 12.0 & 3.4 & TEC \\
Bahir Dar, Ethiopia & BDMT & 37.36 & 11.6 & 2.8 & TEC \\
Addis Ababa, Ethiopia & ADIS & 38.7 & 9.0 & 1.3 & TEC \\
Nazret, Ethiopia & NAZR & 39.3 & 8.6 & -0.25 & TEC \\
Arba Minch, Ethiopia & ARMI & 37.6 & 6.1 & -3.13 & TEC \\
Negele, Ethiopia & NEGE & 39.6 & 5.3 & -3.7 & TEC \\
Eldoret,Kenya & MOIU & 35.4 & 0.5 & -8.93 & TEC \\
Entebbe, Uganda & EBBE & 32.46 & 0.05 & -9.5 & TEC \\
Nairobi, Kenya & RCMN & 36.89 & -1.22 & -10.72 & TEC \\
Malindi, Kenya & MAL2 & 40.2 & -3.0 & -12.4 & TEC \\
Arusha, Tanzania & ARSH & 36.7 & -3.4 & -13.04 & TEC \\
Dodoma, Tanzania & DODM & 35.8 & -6.2 & -16.6 & TEC \\
Tukuyu, Tanzania & TUKC & 33.7 & -9.3 & -19.5 & TEC \\
Mzuzu, Malawi & MZUZ & 34.0 & -11.4 & -21.9 & TEC \\
Zomba, Malawi & ZOMB & 35.3 & -15.4 & -26.1 & TEC \\
Thohoyandou, South Africa & TDOU & 30.4 & -23.1 & -33.8 & TEC \\
Richards Bay, South Africa & RBAY & 32.0 & -28.8 & -38.65 & TEC \\
\hline
\end{tabular}

determine either EEJ or total electron content (TEC). Later in Sect. 2.2, we explained the appropriateness of high solar activity data during 2011-2013 that were used in this study.

In order to cater for the different offset values of different magnetometers, the baseline value $H_{\mathrm{B}}$ of each day was subtracted from the values of $H$ (Yizengaw et al., 2014). For each day, values of $H$ measured at a particular station during 23:00-23:59 LT were averaged to give the $H_{\mathrm{B}}$ value for that day. The values obtained for a specific station after subtracting $H_{\mathrm{B}}$ from $H$ were denoted as $H_{\mathrm{S}}$. To obtain the EEJ $(\Delta H)$, the $H_{\mathrm{S}}$ values calculated at ETHI were subtracted from those of the corresponding days that were calculated at AAE. Most studies on the EEJ report the peak of the diurnal EEJ around 12:00 LT (Gouin, 1962; Venkatesh et al., 2015; Yizengaw et al., 2014; Subhadra Devi and Unnikrishnan, 2014). In line with this information, the daytime EEJ strength for each day in this study was represented by the mean of the EEJ during the period 10:00-13:00 LT, when the peak of the daytime EEJ is expected to occur.

\subsection{Determination of EIA strength}

The EIA strengths were calculated using data obtained from Global Navigation Satellite System (GNSS) receivers along the $30-40^{\circ}$ longitude sector of Africa. The stations are represented with black dots in Fig. 1. The latitude range of the stations considered were mainly restricted to the south of the dip equator. However, a few stations slightly north of the dip equator were considered to allow us to locate the trough of the EIA over the region. The Receiver INdependent EXchange (RINEX) data files of the receivers were obtained from the University NAVstar COnsortium (UNAVCO) website (ftp://data-out.unavco.org/pub/rinex/, last access: 15 September 2017). Data of geomagnetically quiet days $(\mathrm{Kp} \leq 3)$ were considered. The development of the EIA during disturbed conditions could be examined in a separate study since it involves additional mechanisms such as the prompt penetration of magnetospheric electric fields and the disturbance dynamo electric fields.

Table 2 shows the number of geomagnetically quiet days when the magnetometers at ETHI and AAE and seven of the GNSS receivers (ADIS, ARMI, MOIU, RCMN, EBBE, MAL2 and DODM) listed in Table 1 were simultaneously operational. Dashes in the table depict unavailability of data. Considering the fact that the formation of the EIA depends on solar activity (e.g. Yue et al., 2015), we grouped the data into low (2008 and 2010) and high (2011-2013) solar activity periods. This grouping might minimise the effect of solar activity on the correlation between EIA and EEJ. For statistical analysis, it appears that the amount of data of low solar activity period shown in Table 2 is not sufficient. Therefore, in this study, we used data of the high solar activity years of 2011-2013.

The RINEX files were processed using GPS-TEC analysis application software (Seemala and Valladares, 2011) to obtain the daily vertical TEC (VTEC) data over a station with $30 \mathrm{~s}$ resolution. In this study, to minimise multi-path effects, 
Table 2. Number of days in which magnetometers and some GNSS receivers used were simultaneously operational.

\begin{tabular}{lrrrrr}
\hline & 2008 & 2010 & 2011 & 2012 & 2013 \\
\cline { 2 - 6 } Month & \multicolumn{5}{c}{ No. of days } \\
\hline January & - & - & 20 & 16 & 16 \\
February & - & 7 & 20 & 11 & 9 \\
March & - & 14 & 15 & 8 & 6 \\
April & - & 7 & 7 & 12 & 16 \\
May & - & - & 10 & 17 & 2 \\
June & - & 19 & 14 & 6 & 8 \\
July & - & 23 & 12 & 8 & 11 \\
August & 12 & 8 & 11 & 11 & 7 \\
September & 12 & 5 & - & 14 & 1 \\
October & 14 & 13 & - & 18 & - \\
November & 18 & 18 & 2 & 18 & - \\
December & - & - & 24 & - & - \\
\hline
\end{tabular}

we used data of satellites with elevation angles greater than $25^{\circ}$ (Mungufeni et al., 2016). The daily VTEC data were analysed in two ways. In the first analysis, we computed monthly mean TEC over a station as described in the following procedure. The daily VTEC data for all the days within the study period were binned according to months. Therefore, 12 monthly bins were formed from the data during the period 2011-2013. The monthly bins were further binned according to LT. The mean values of the LT bins were determined to yield monthly mean TEC with $30 \mathrm{~s}$ resolution. In the second analysis, we computed the EIA strengths. Various studies have represented EIA strength in many ways, including (i) computing the difference of TEC measured at the crest and that at the trough (Sastri, 1982), (ii) determining the normalised difference of TEC measured at the crest and that measured at the trough (Sastri, 1982), (iii) simply using the peak of TEC measured at the crest (Venkatesh et al., 2015) and (iv) determining the ratio of TEC measured at the crest to that measured at the trough (Zhang et al., 2009; Yue et al., 2015), referred to as the CT: TEC ratio. Unlike methods (i) and (ii) which might produce both negative and positive EIA strengths, the last two methods only yield positive values. For the convenience of only working with positive values, method (iv) was used to determine the EIA strength in this study. The advantage of CT: TEC ratio over methods (i) and (iii) is that it provides a relative variability of the EIA, which usually represents variability of a physical phenomenon well.

\section{Results and discussions}

\subsection{Occurrence of the EIA}

We illustrate the occurrence of the EIA over the region by contour plots of monthly mean TEC as a function of magnetic latitude and LT. The monthly mean TEC plotted values were obtained from the 19 GNSS receiver stations listed in Table 1. The contour plots helped in determining the location of the trough and the region of the crest over the East African sector. Figure $2 \mathrm{a}-\mathrm{j}$ are for the months of November and January-September. The panels for the months of October and December are missing because these months do not have data over several stations. The data gaps would limit observation of the EIA features over the region. In Fig. 2, the colour bar ranges from blue (low TEC) to red (high TEC). The white spaces within a panel indicate missing data.

In Fig. 2, the EIA appears to start forming at about 09:00 LT, existing up to 20:00 LT. Although their data did not cover the low-latitude regions sufficiently, Appleton (1946) showed that the noontime critical frequency in the F2 layer appears to increase with higher values of dip latitude. Further, Sethia et al. (1980) stated that latitudinal variation of TEC in the previous studies indicates the existence of an equatorial anomaly in TEC, in its latitudinal variation, similar to the one in F2 region critical frequency. Therefore, the observation of occurrence of the EIA during 09:00-20:00 LT over the East African region is in line with these stated observations. In equinox months (February-April, August, September) and November, clear occurrence of the EIA exists beyond 20:00 LT, lasting till 24:00 LT (see Fig. 2). Various authors have found different time delays that exist between intense EEJ strength and the occurrence of the prominent EIA. For instance, an approximate time delay of 2-3 and $4 \mathrm{~h}$ were reported by Rush and Richmond (1973) and Venkatesh et al. (2015), respectively. Since the peak of the EEJ occurs at around 12:00 LT, the cases of prominent EIA about $8 \mathrm{~h}$ later (during 20:00-24:00 LT) might not be due to increased zonal electric fields associated with increased EEJ. Other factors such as the PRE just before this period might be a probable cause. Moreover, Sastri (1990) stated that although the formation of the EIA is primarily due to the fountain effect, many intricate features of the EIA morphology can be influenced by neutral meridional winds at $\mathrm{F}$ region altitudes. Probably due to the prolonged fountain effect, the EIA observed during 20:00-24:00 LT has a wider trough compared to that observed during 09:00-20:00 LT. From this point onwards, we shall not discuss the cases of the EIA during 20:00-24:00 LT, since the focus of this study as stated before is the statistical analysis of the correlation between daytime EEJ strength and the occurrence of the daytime EIA.

Most of the panels in Fig. 2 except that of November and April indicate that the trough of the EIA exists between 0 and $4^{\circ} \mathrm{S}$, covering locations of ARMI, NAZR, and NEGE. This slight southward shift of the trough appears to be in line with the fact that both the EEJ and CEJ exhibit large latitudinal excursions (exceeding mag. lat. $1^{\circ}$ ) on different days as well as at different hours of the same day (Kane and Trivedi, 1982). The normal EEJ over the East African region is generally centred over the magnetic latitude range of $0-0.5^{\circ} \mathrm{S}$ (Kane and Rastogi, 1977). Based on this information, we tentatively suggest that over the East African region, $\boldsymbol{E} \times \boldsymbol{B}$ drifts over 
(a) November

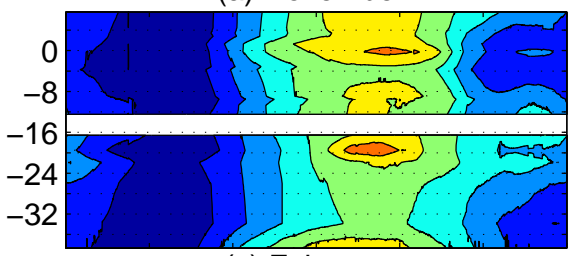

(c) February

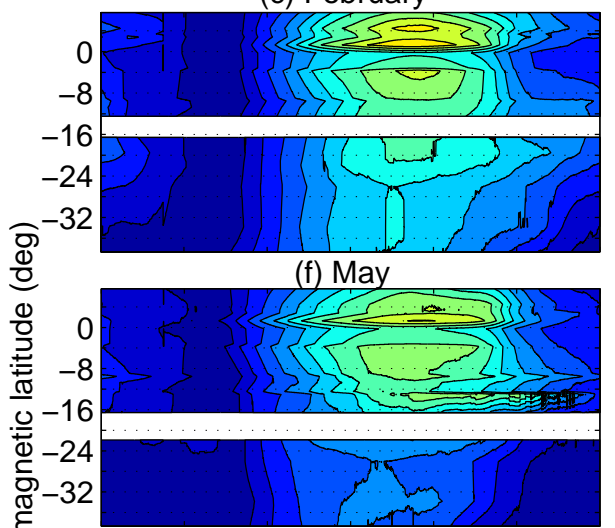

(i) August

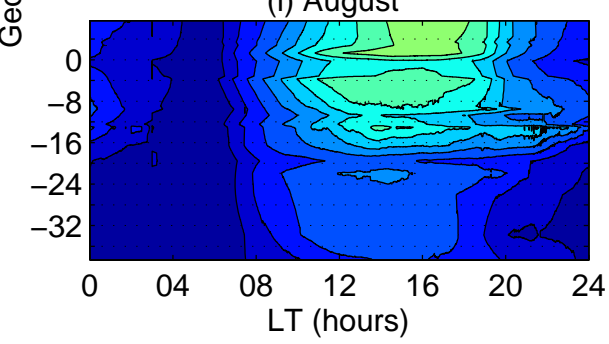

(b) January

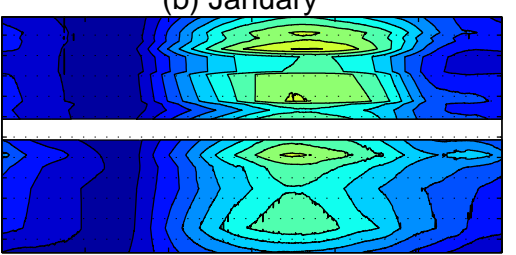

(d) March

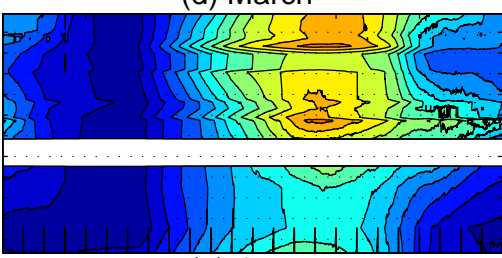

(g) June

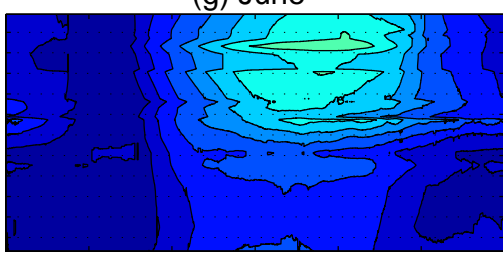

(j) September
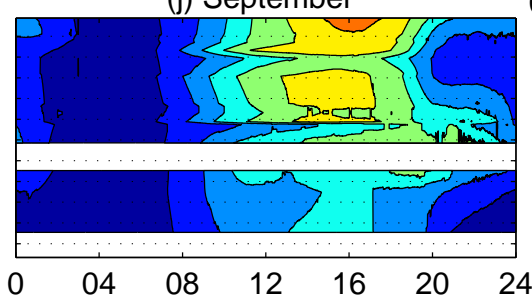

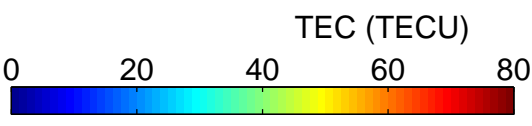

(e) April

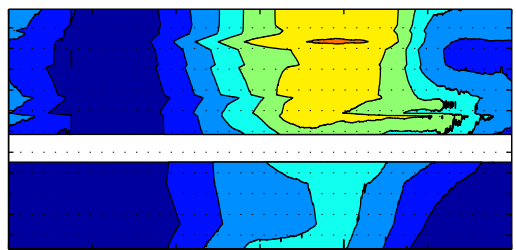

(h) July

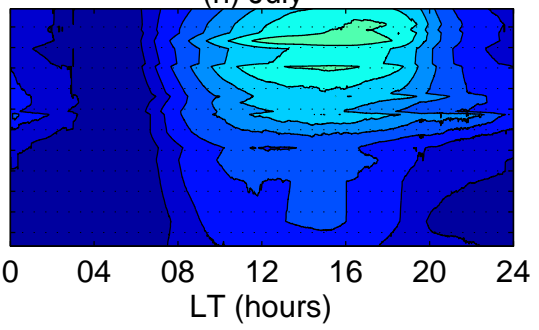

Figure 2. Contour plots of monthly mean TEC as a function of latitude and LT. (a-j) are for November and January-September.

the magnetic latitude range of $0-4^{\circ} \mathrm{S}$ are the strongest compared to other latitudes. This implies that over the region, the location where the fountain effect is triggered lies slightly south of the magnetic equator.

In Fig. 2, the southern crest appears to exist from 4 to $19^{\circ} \mathrm{S}$, covering locations of MOIU, EBBE, RCMN, MAL2, ARSH, DODM and TUKC. Among the stations at the trough, ARMI appeared to have more data. Therefore, in our calculation of EIA strengths, the VTEC over ARMI was considered as that of the trough, while the VTEC over other stations with latitudes ranging $8-19.5^{\circ} \mathrm{S}$ were considered as VTEC data at the crest. Our results during the high solar activity period of 2011-2013 differ in some aspects from the study done during the low solar activity year of 2009 reported by Bolaji et al. (2017). For instance, their study revealed that the daytime EIA occurrence rarely exceeds 18:00 LT and there was practically no occurrence of the EIA past this time. The highest strength of TEC at the southern crest depicted by their study was about $50 \mathrm{TECU}$, while our results demonstrated approximately 80 TECU. Whereas the inner edge of the southern crest they established was slightly further from the magnetic equator $\left(\sim 17^{\circ} \mathrm{S}\right)$, our results indicated the same close to the magnetic equator $\left(4^{\circ} \mathrm{S}\right)$. The increased electron density close to the magnetic equator we observed might be due to ionisation resulting from the location of the sun above the southern crest close to the zenith. Otherwise, during high solar activity conditions the EEJ values are expected to increase. This should have originated from the increased zonal electric field which results in the increased EIA when plasma is transported far from the magnetic equator.

Another important feature worth mentioning in our Fig. 2a, b, $d$ and e is the occurrence of a second southern EIA crest spanning the magnetic latitude $\sim 28-40^{\circ} \mathrm{S}$. Figures 4 and 5 of Bolaji et al. (2017) also depict these features over the southern low- and mid-latitude regions of East Africa. However, their emphasis was on the same feature that was observed north of the magnetic equator. They suggested that these scenarios could result from inconsistent transportation of plasma to higher latitudes. In the next section, we compared the worldwide morphology of the EIA using the IRI model. 

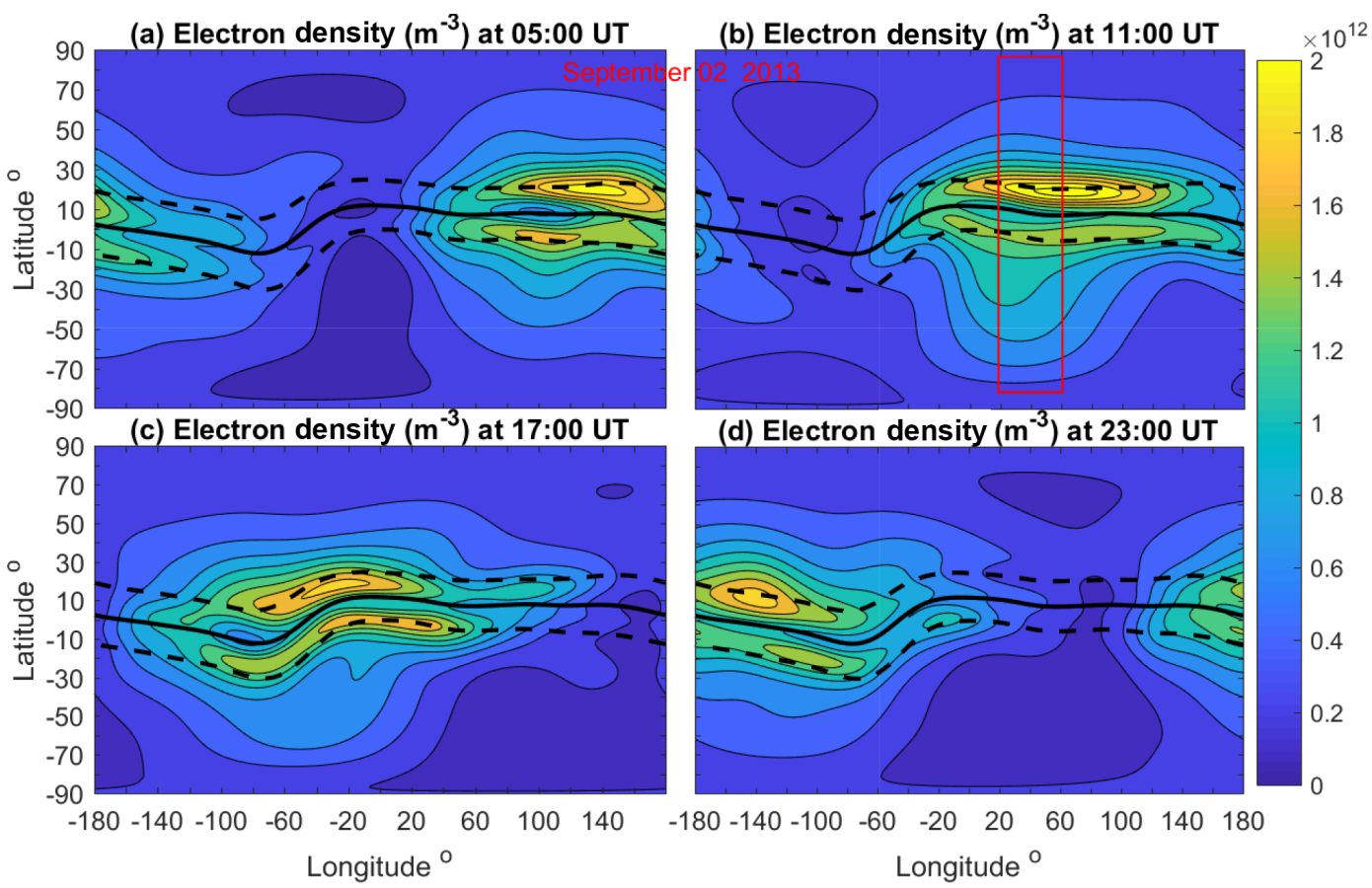

Figure 3. Panels (a), (b), (c) and (d) present the global distribution of electron density derived from the IRI model at 05:00, 11:00, 17:00 and 23:00 UT, respectively on 2 September 2013. The black solid and dotted lines indicate the locations of the magnetic equator and the crests of the EIA. The red box indicates the longitude sector of the current study region.

\subsection{EIA morphology depicted by International Reference Ionosphere (IRI) model}

For the international standard specification of ionospheric parameters, the Committee On Space Research (COSPAR) and the International Union of Radio Science (URSI) recommended the IRI model. The model is primarily developed using data sources, such as the (i) worldwide network of ionosondes and incoherent scatter radars, (ii) ISIS and Alouette topside sounders and (iii) in situ instruments flown on satellites and rockets (http://irimodel.org/, last access: 1 May 2018). However, theoretical considerations have been used in bridging data gaps and for internal consistency checks (Bilitza, 2001). In order to verify our observations of a southward displacement of the EIA trough, we used global snapshots of the EIA morphology depicted by the IRI 2012 model at an altitude of $100 \mathrm{~km}$. Figure $3 \mathrm{a}, \mathrm{b}, \mathrm{c}$ and d present the distribution of electron density as a function of longitude and latitude at 05:00, 11:00, 17:00 and 23:00 UT, respectively on 2 September 2013. The selection of this date aimed at identifying a year and season when high chances of EIA occurrence exist. This particular date considered was geomagnetically quiet since the study only analysed data during such conditions. It is important to note that we specified the date and geographic coordinates, while the rest of the input parameters required by the model were provided by the default option in the model. In Fig. 3, the red box indicates the longitude range $20-60^{\circ}$, where our region of study lies.
The black solid and dashed lines indicate the location of the magnetic equator and the nominal location of the EIA crests, respectively. The colour bar ranges from blue to yellow, indicating low and high electron densities, respectively.

Within the red box in Fig. 3b, it can be seen that the trough is not symmetrical over the magnetic equator. This seems to support our observation of the EIA trough over the East African region being displaced slightly southward. The location of the EIA trough is symmetrical over longitudes $\sim 100^{\circ}$ (Fig. 3a) and the range from -80 to $-60^{\circ}$ (Fig. 3c and d), while it is slightly displaced southward over the longitude range from -20 to $20^{\circ}$ (Fig. 3c) and 20 to $60^{\circ}$ (Fig. 3b). Figure $3 \mathrm{a}$ appears to show that, over India, at a longitude of $\sim 80^{\circ}$, the EIA trough centre lies south of the magnetic equator. This is in line with the result that over Indian region, the dip latitude of the centre of the EEJ is $\sim-0.19^{\circ}$ (Rabiu et al., 2012). More time is needed to check over other longitude sectors if the alignment of the EIA trough with respect to the magnetic equator is similar to that of the EEJ. Otherwise, based on the cases observed over Africa and India, we suggest that the location of the EIA trough over a particular longitude depends on the alignment of the centre of the EEJ with respect to the magnetic equator.

Next, we present the fairly long-term trend of occurrence of the EIA simultaneously with the corresponding trend of the EEJ over East Africa. This allowed us to clearly visualise the effect of the EEJ on the occurrence of the EIA. 


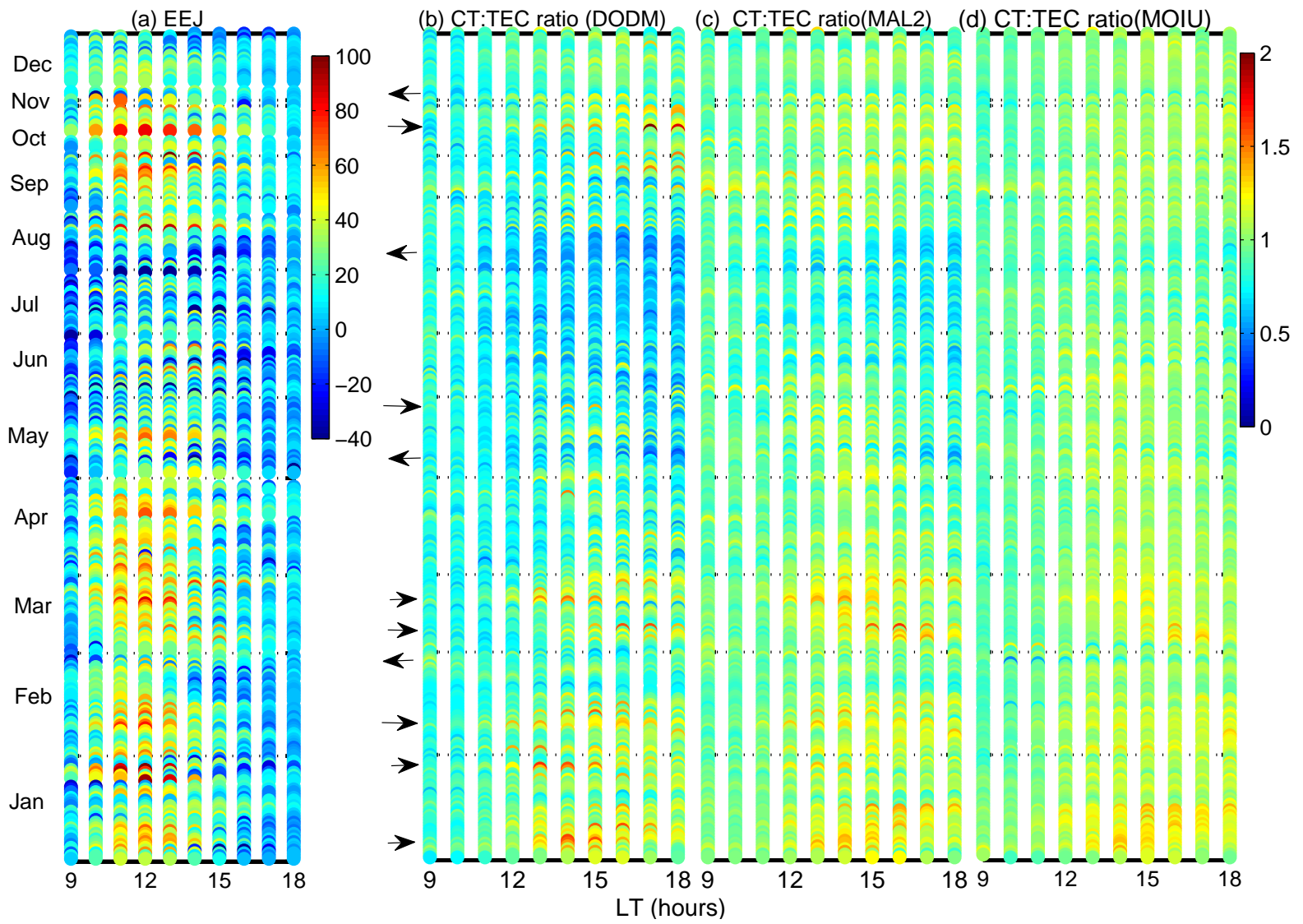

Figure 4. Panel (a) shows variation of the hourly EEJ as a function of LT during days in monthly bins. Corresponding CT : TEC ratios over DODM, MAL2 and MOIU are shown in (b-d), respectively. Arrows pointing right and left indicate some cases of the prominent EIA during the strong daytime EEJ and the background-level EIA during the weak daytime EEJ, respectively.

\subsection{Simultaneous observations of EEJ and EIA strengths}

The hourly EIA strengths were used to constitute the daily EIA strengths. The maximum CT: TEC ratio in a $1 \mathrm{~h}$ interval could be used to represent the EIA strength in that interval. Since such values are prone to errors, the upper quartile, which is close to the maximum value, was used for such representation. The development of the EIA exhibits a diurnal pattern that is dependent on the phase of the solar activity cycle (Rush et al., 1969; Sastri, 1990). At the solar maximum, though the formation of the crests takes place around 09:00 LT, the crests continue to develop and move polewards throughout the day till around 20:00 LT. Based on this idea and the fact that the EEJ is a daytime phenomenon, the local time intervals considered to determine hourly EIA strengths (upper quartile of CT: TEC ratios in a $1 \mathrm{~h}$ interval) in a day in this study ranged from 09:00 to 18:00 LT. The daily EIA strengths for the entire study period (2011-2013) were binned according to months, yielding 12 monthly bins. In a similar way, hourly EEJ strengths were also computed to constitute daily values, which were then binned based on months.

Figure 4 presents the daily EEJ strengths (panel a) and the corresponding EIA strengths over DODM (panel b), MAL2 (panel c) and MOIU (panel d). The horizontal dotted lines separate data of the various monthly bins which are labelled on the vertical axis. The colour bar between panels (a) and (b) ranges from blue (low EEJ) to red (high EEJ). In the case of the colour bar to the right of panel (d), blue denotes a low CT: TEC ratio, while red denotes a high CT: TEC ratio. For the sake of illustration and making sure that the southern crest is well covered, the three stations (DODM, MAL2 and MOIU) are almost separated by about $4^{\circ}$ magnetic latitude and are well distributed over the southern crest.

Most of the days in the monthly bins appear to show occurrence of the EIA (CT: TEC ratio $>1$ ). This may be due to the existence of a daily daytime eastward electric field due to the global $\mathrm{E}$ region dynamo driven by tidal winds. The resulting ever-present upward $\boldsymbol{E} \times \boldsymbol{B}$ drift lifts plasma to higher altitudes, which then diffuses north and south along magnetic field lines as well as downwards, resulting into the EIA observed over the stations. As discussed in Sect. 3.1, 
there are many other factors that may disturb this mechanism of EIA formation, which in turn limits observation of the EIA on some days. It can be deduced from Fig. $4 \mathrm{~b}-\mathrm{d}$ that a CT: TEC ratio $\geq 1$ signified prominent occurrence of the EIA (TEC over the crest exceeds that over the trough by a factor $\geq 1$ ). By visual inspection of Fig. 4, it is difficult to relate the variations in occurrence of the EIA at background levels (CT : TEC ratio $<1$ ) over the stations with that of daytime EEJ strength. However, the conspicuous cases when high EEJ strength $(\geq 50 \mathrm{nT})$ simultaneously occurs with the prominent EIA are clearly visible over MAL2 and DODM. Some of the cases are marked in Fig. 4, with arrows pointing to the right. The arrows pointing to the left in Fig. 4 depict cases when throughout the day, low values of EEJ $(<50 \mathrm{nT})$ and EIA strengths $(\mathrm{CT}$ : TEC ratios $<1$ ) are measured simultaneously.

Figure 5 is a zoom-in of Fig. 4 for the months of February and December. In the figure, the vertical numbers indicate the number of days in the monthly bin. The arrows pointing left in December and February in Fig. 4 correspond to day 1 of the December bin and day 34 of the February bin in Fig. 5, respectively. The arrow pointing right in February in Fig. 4 corresponds to day 11 of February in Fig. 5. These three examples clearly show that high EEJ strengths occur simultaneously with the prominent EIA. This observation is similar to the one made by Bolaji et al. (2017). Their results showed experimental evidence of how EEJ strength, which is a proxy of $\boldsymbol{E} \times \boldsymbol{B}$ drift, mostly controls plasma transportation over low latitudes. Usually, low values of $\boldsymbol{E} \times \boldsymbol{B}$ drifts result in poor formation of the EIA (Yizengaw et al., 2014; Olwendo et al., 2015).

Three other general observations can be made from Fig. 4 . (i) The occurrence of the prominent EIA during daytime was fairly common in equinox seasons (February, March, April, September and October) compared to solstice seasons (May, June and July). Along $120^{\circ}$ longitude, Zhang et al. (2009) made similar observations. They reported that the EIA strength showed a semi-annual variation, with maximum peak values occurring in the equinoctial months. Moreover, Sethia et al. (1980) used data measured over India during the low solar activity year of 1975 to show that EEJ effects on TEC and $N m \mathrm{~F} 2$ due to the associated zonal electric fields are much more pronounced in the equinoxes than in winter and summer. (ii) The EEJ and EIA strengths are weaker in the June solstice compared to other seasons. This is consistent with the results of Yizengaw et al. (2014). (iii) The highest values of EEJ and EIA strengths appear to occur approximately during 11:00-13:00 and 13:00-18:00 LT, respectively. In the next subsection we examine the correlation between the hourly EIA strengths and daytime EEJ strength.
Table 3. Number of samples used to compute correlation coefficients.

\begin{tabular}{lrrrrr}
\hline Season & \multicolumn{5}{c}{ Number of samples } \\
\cline { 2 - 6 } & MOIU & EBBE & RCMN & MAL2 & DODM \\
\hline MEQX & 54 & 43 & 40 & 56 & 56 \\
JSLT & 27 & 37 & 27 & 37 & 37 \\
SEQX & 26 & 25 & 19 & 26 & 26 \\
DSLT & 50 & 59 & 24 & 61 & 61 \\
\hline
\end{tabular}

\subsection{The correlation between daytime EEJ and EIA strengths}

In order to determine the correlation between daytime EEJ and EIA strengths, the daily EIA strengths (data similar to that plotted in panels (b)-(d) of Fig. 4) were first binned into the March equinox (March and April), the June solstice (June and July), the September equinox (September and October) and the December solstice (December and January). These seasons were denoted as MEQX, JSLT, SEQX and DSLT, respectively. The seasonal bins were further binned according to local time, with a window size of $1 \mathrm{~h}$. The values of EIA strengths at every local time bin were then correlated with the values of the daytime EEJ strength (mean of the EEJ during the period 10:00-13:00 LT) of the corresponding days. Figure 6 presents the variation of the correlation coefficients as a function of LT in MEQX (blue), JSLT (green), SEQX (yellow) and DSLT (black). Panels (a)-(e) are for the coefficients that were determined over MOIU, EBBE, RCMN, MAL2 and DODM, respectively. These stations lie within the first southern EIA crest and they are among the seven GNSS stations which were used to construct Table 2. Correlation coefficients for stations such as ARSH and TUKC were not presented because of insufficient data. Regarding the second southern crest seen in Fig. 2, in addition to stations lying there not having enough data, its occurrence does not seem to be dominant in any of the months.

After filtering the data of days with the afternoon CEJ, unrealistic values of daytime EEJ and EIA strengths, the number of samples over a particular station remained almost constant at all LT bins for a specific season. The afternoon CEJ days were identified when the EEJ values remained negative consecutively for $\geq 2 \mathrm{~h}$ during 14:00-18:00 LT (Reddy, 1989; Hajra et al., 2009; Rastogi, 1974). Although it still needs to be investigated, we assumed that the morning CEJ might not affect EIA development significantly. The number of samples used to compute the correlation coefficients that are presented in Fig. 6 are shown in Table 3.

Most of the $r$ values presented in Fig. 6 are significant (the probability $p$ for the correlations are $<0.05$. The $p$ values are not presented here). It may not be meaningful to associate the cases of non-significant $r$ in this study with low number of samples since the number of samples in a particular season 


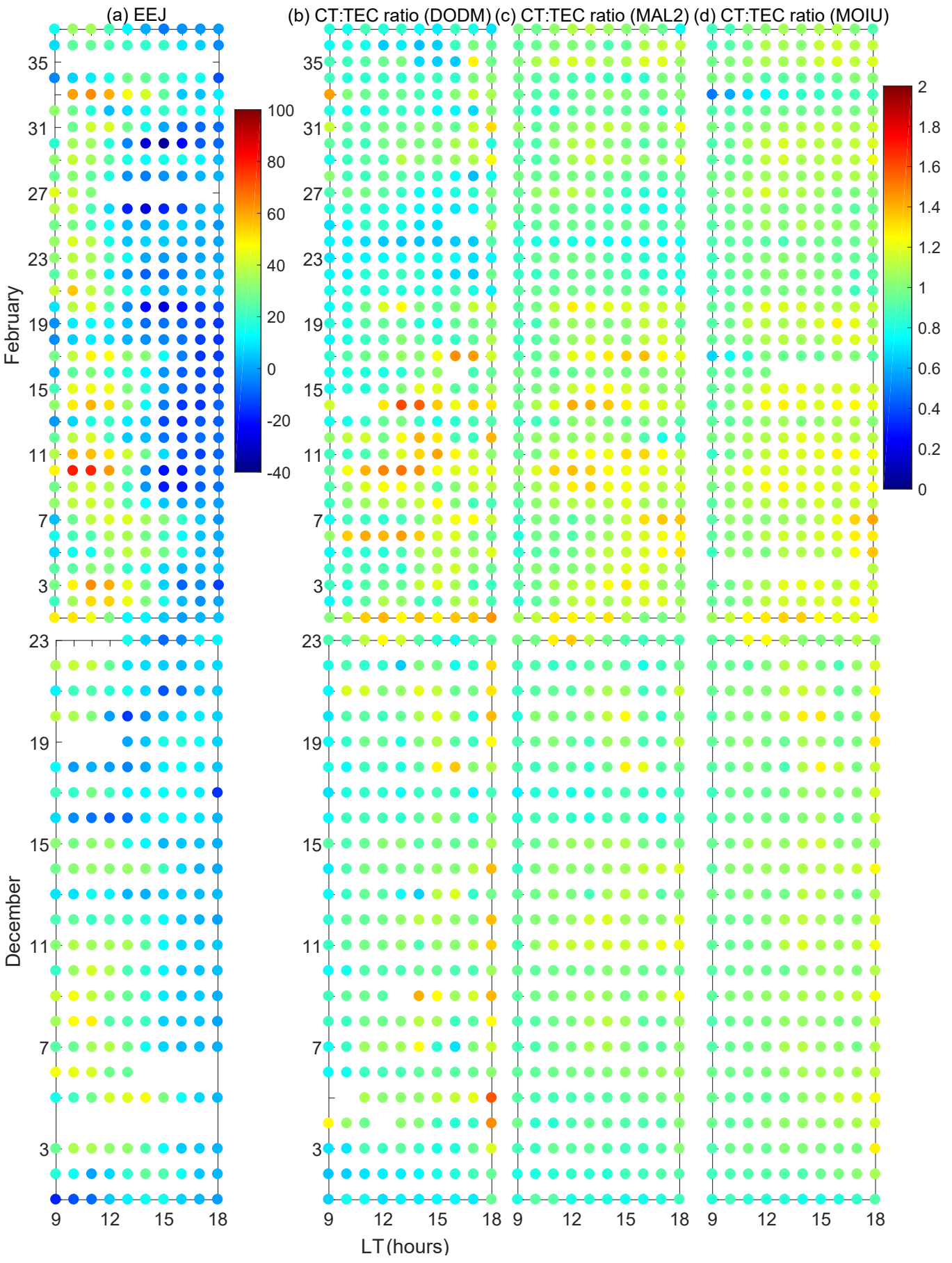

Figure 5. A zoom-in of Fig. 4 for the months of February and December.

does not vary with LT, yet both cases of significant and nonsignificant $r$ values exist during all the seasons. However, we noted that the cases of non-significant $r$ values mostly occur when occurrence of the EIA does not seem to be influenced by the strength of the EEJ ( $r \leq 0.3$, which occur mostly during periods $<11: 00$ and $>16: 00 \mathrm{LT}$ ).
Overall, Fig. 6 shows that $r$ values appear to be positive and increasing from 09:00 up to 13:00 LT when the peak occurred and then decreasing gently till 18:00 LT. The average $r$ values during 13:00-15:00 LT indicate strong positive correlations $(r \geq 0.5)$ over East Africa. This result is similar to that reported by Rush and Richmond (1973). They found that, over the American sector, in October of the high solar activ- 


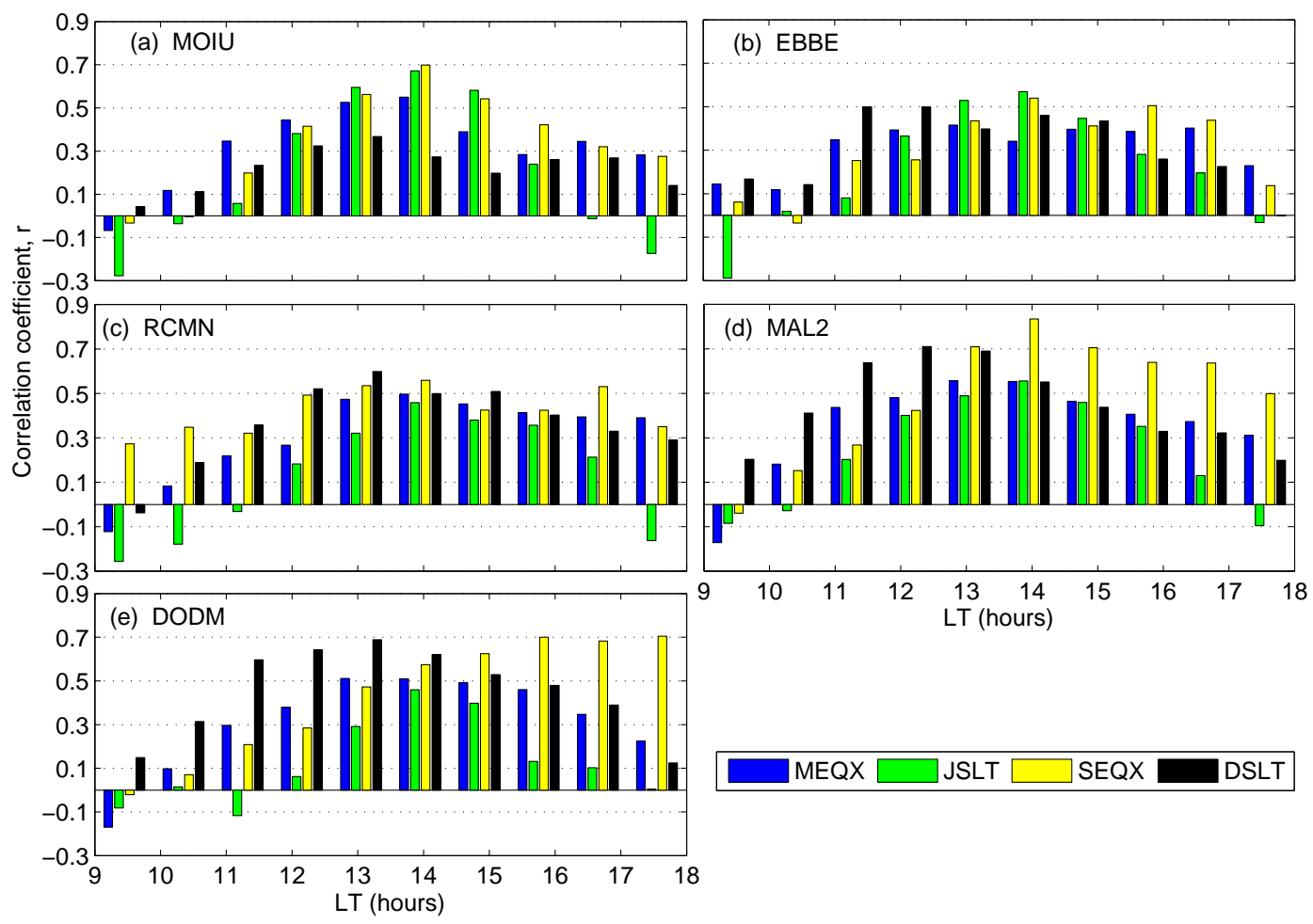

Figure 6. The LT variation of correlation coefficients between hourly EIA strength and daytime EEJ strength in MEQX (blue), JSLT (green), SEQX (yellow) and DSLT (black). Panels (a-e) are for correlation coefficients over MOIU, EBBE, RCMN, MAL2 and DODM, respectively.

ity year of 1958 , the correlation coefficients between the EIA and EEJ parameters maximised during 13:00-15:00 LT. The unique feature presented by Fig. 6 is the strong positive correlations in SEQX over MAL2 and DODM that remained till 18:00 LT. This point needs further investigation. However, it can be noted that these two stations are far from the magnetic equator compared to the remaining three. Moreover, they are closer to the nominal southern crest of the EIA at $15^{\circ} \mathrm{S}$.

Based on the general trend, the occurrence of strong positive correlations during 13:00-15:00 LT between the EIA and the daytime EEJ strength is consistent with the idea that the EIA maximises about a few (2-4) hours from the time of the intensified cause. In this case, the cause might be the increased zonal electric field manifested in the EEJ that appeared to peak during 11:00-13:00 LT (see Fig. 4). There is no clear trend in the $r$ values that are related to the seasonal and latitudinal variations. There might be an average value of daytime EEJ strength above which chances of prominent zonal electric field and EIA occurrence might be high. In the next subsection, we illustrate how such a value can be determined.

\subsection{A threshold EEJ strength}

As deduced from Fig. 4, cases of daytime prominent EIA might be associated with the EEJ $\geq 50 \mathrm{nT}$. The approximate values for each station considered in this study were deter-
Table 4. Percentage of prominent EIA corresponding to threshold EEJ strength.

\begin{tabular}{lrrrrr}
\hline Season, LT & \multicolumn{5}{c}{ Station } \\
\cline { 2 - 6 } & MOIU & EBBE & RCMN & MAL2 & DODM \\
\hline MEQX, 13:00 & 97 & 80 & 86 & 94 & 43 \\
SEQX, 13:00 & 91 & 81 & 60 & 100 & 45 \\
DSLT, 13:00 & 100 & 95 & 100 & 100 & 95 \\
MEQX, 14:00 & 100 & 83 & 86 & 86 & 50 \\
SEQX, 14:00 & 100 & 90 & 80 & 91 & 64 \\
DSLT, 14:00 & 100 & 100 & 100 & 100 & 90 \\
MEQX, 15:00 & 97 & 87 & 82 & 86 & 56 \\
SEQX, 15:00 & 91 & 73 & 80 & 82 & 73 \\
DSLT, 15:00 & 95 & 100 & 100 & 86 & 95 \\
\hline
\end{tabular}

mined by examining most of the data for the entire study period. We extracted all the values of daytime EEJ strength that corresponded to hourly prominent EIA strengths over MOIU, EBBE, RCMN, MAL2 and DODM (i) during the equinox and DSLT seasons (when chances of prominent EIA were high) and (ii) at 14:00 LT (chances of $r>0.5$ are high). As shown later in Table 4, similar results would be obtained at 13:00 or 15:00 LT. Figure 7a-e present the frequency distribution of the various ranges of EEJ strengths over MOIU, EBBE, RCMN, MAL2 and DODM, respectively. On the 


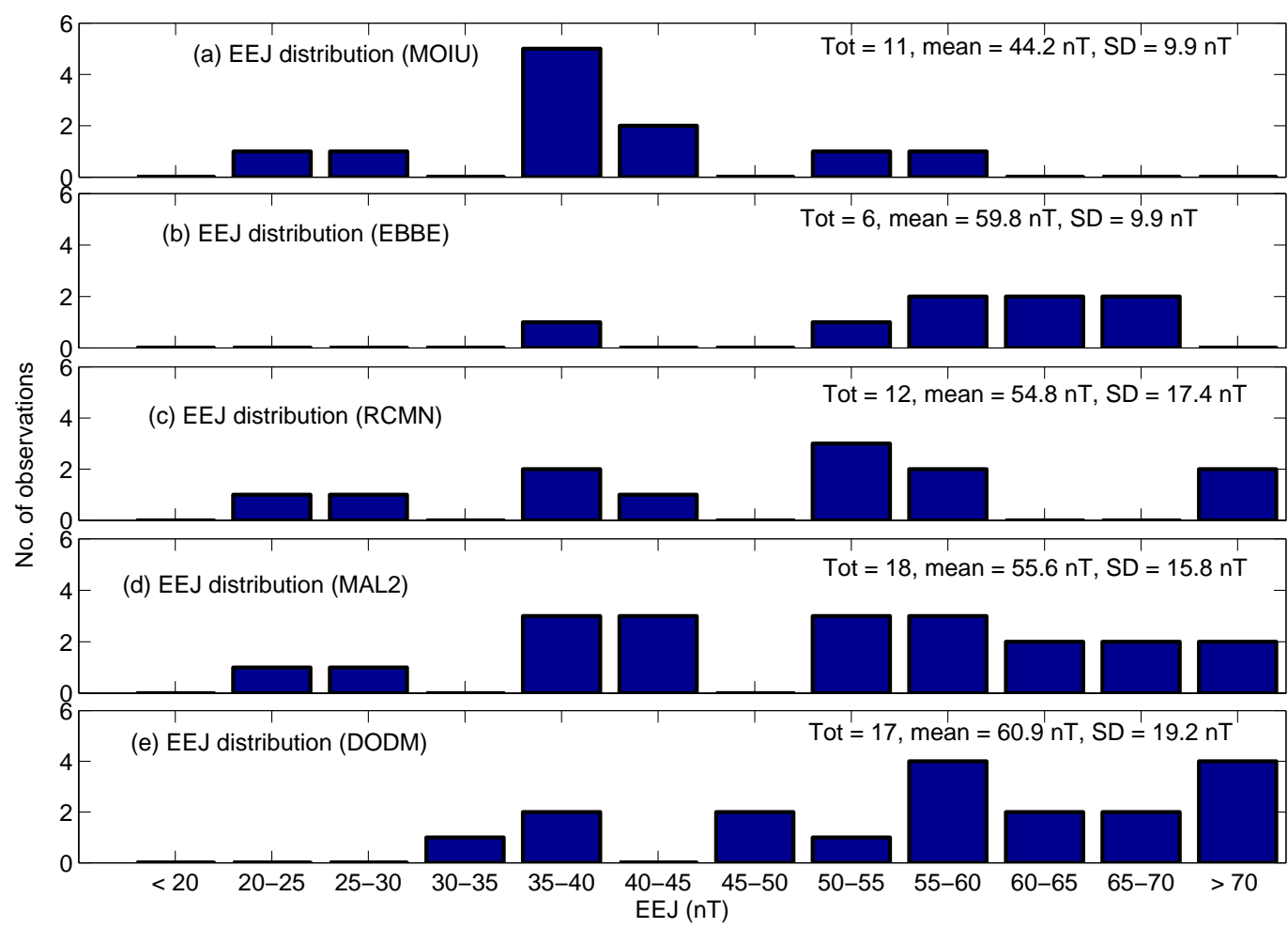

Figure 7. The distributions of EEJ strengths associated with prominent EIA at 14:00 LT over (a) MOIU, (b) EBBE, (c) RCMN, (d) MAL2, and (e) DODM.

right of each panel, the total number (Tot), mean and standard deviation (SD) of the EEJ values are indicated. It can be observed from the panels that the mean EEJ at which the prominent EIA occurred ranged from 44.2 to $60.9 \mathrm{nT}$ (overall mean $55.1 \mathrm{nT}$ ), while the SD ranged from 9.9 to $19.2 \mathrm{nT}$ (overall $\mathrm{SD} 14.4 \mathrm{nT}$ ). Therefore, over the East African sector, the EIA might occur prominently during 13:00-15:00 LT when measurements of the EEJ $\geq 40.7 \mathrm{nT}$ (overall mean EEJ - overall $\mathrm{SD})$ are made.

The suitability of the EEJ threshold value ( $40.7 \mathrm{nT}$ ) to predict occurrence of the EIA was ascertained. This was again done for MEQX, SEQX and DSLT when high chances of prominent EIA occurrence were expected. The number of observed EIA occurrences (CT: TEC ratio $>1$ ) during days with EEJ strength $\geq 40.7 \mathrm{nT}$ were determined for each season and station. These were denoted as NoPromEIA. The total number of observed EIA strengths (including both a $\mathrm{CT}$ : TEC ratio $\leq 1$ and a CT: TEC ratio $>1$ ) during days with EEJ strength $\geq 40.7 \mathrm{nT}$ were also determined and denoted as TotalNoEIA. The ratios of NoPromEIA to TotalNoEIA were expressed as percentages. Table 4 presents the percentages that were determined over MOIU, EBBE, RCMN, MAL2 and DODM. In the table, column 1 presents the seasons and the three local times 13:00, 14:00 and 15:00 at which the percentages were determined. At 13:00, 14:00 and 15:00 LT, the fractions of the number of entries with per- centages $>80$ were $12 / 15,13 / 15$ and $12 / 15$, respectively. Therefore, the percentages at the three local times $(13: 00$, 14:00 and 15:00 LT) were similar. These fractions indeed confirm the fact that the chances of observing prominent EIA occurrence are high when measurements of EEJ strength of at least $40.7 \mathrm{nT}$ are made. This appears to be the first time that a threshold value of the EEJ over the East African region has been determined that can be associated with the zonal electric field, which in turn produces the pronounced EIA.

\section{Conclusions}

We have established the statistics of the correlation between daytime EEJ strength and the occurrence of the EIA over the East African sector. The main results of this study are as follows. (i) The chances of prominent EIA occurrence were high in equinoctial and December solstice seasons. (ii) Generally, the EIA strengths were weaker in the June solstice compared to other seasons. (iii) The daytime EIA strengths were mostly positively correlated $(r>0)$ with daytime EEJ strength. Particularly, strong positive correlations $(r \geq 0.5)$ were observed mostly during 13:00-15:00 LT. These first three results are similar to the ones reported in the previous studies based on data from other regions (Rush and Richmond, 1973; Zhang et al., 2009; Sethia et al., 1980). In addition to confirming that the results over the East African re- 
gion are consistent with those reported over other regions by the previous studies, the next two results appear to be novel. (iv) Over the East African region, the trough of the EIA during high solar activity and quiet geomagnetic conditions lies slightly south $\left(0-4^{\circ} \mathrm{S}\right)$ of the magnetic equator. We suggest that the slight southward shift of the EIA trough is consistent with the general centre of the EEJ. The latter is also shifted slightly south of the magnetic equator. (v) During the equinox and December solstice seasons, and the local time interval of 13:00-15:00, the probability of observing the EIA on days with daytime EEJ strength $\geq 40 \mathrm{nT}$ was mostly $>80 \%$. It should be noted that these results pertain to a high solar activity period in the ascending phase of Solar Cycle 24. They might change in the seasons of a solar minimum period. This was not done due to unavailability of geomagnetic field measurements over the East African region.

Data availability. The data used in this study were obtained from ftp://data-out.unavco.org/pub/rinex/, http: //swdcwww.kugi.kyoto-u.ac.jp/, http://www.intermagnet.org, last access: 15 September 2015, http://magnetometers.bc.edu, last access: 15 September 2017 and http://spidr.ionosonde.net/spidr/, last access: 1 May 2018.

Competing interests. The authors declare that they have no conflict of interest.

Acknowledgements. Patrick Mungufeni is thankful to his scientific coordinator at the Abdus Salam International Centre for Theoretical Physics (ICTP), Sandro Radicella. Through the associateship scheme with ICTP and with the help of Sandro Radicella, Patrick Mungufeni attended many workshops/conferences organised by ICTP in the research field of this manuscript. The knowledge obtained during the workshops and the interaction with other scientists helped in formulating the problem presented in this study. John Bosco Habarulema's contributions were supported by the South African National Research Foundation (NRF) grant 105778. The International Science Programme of Sweden supported the contributions of Edward Jurua.

The topical editor, Dalia Buresova, thanks two anonymous referees for help in evaluating this paper.

\section{References}

Abdu, M. A.: The International Equatorial Electro-jet Year, AGU, EOS transactions, 73, 49-64, 1992.

Anderson, D., Anghel, A., Yumoto, K., Ishitsuka, M., and Kudeki, E.: Estimating daytime vertical $\boldsymbol{E} \times \boldsymbol{B}$ drift velocities in the equatorial F-region using ground-based magnetometer observations, Geophys. Res. Lett., 29, 12, 37-1-37-4 https://doi.org/10.1029/2001GL014562, 2002.

Anderson, D., Anghel, A., Chau, J., and Veliz, O.: Daytime vertical $\boldsymbol{E} \times \boldsymbol{B}$ drift velocities inferred from ground-based mag- netometer observations at low latitudes, Space Weather, 2, https://doi.org/10.1029/2004SW000095, 2004.

Appleton, E. V.: Two Anomalies in the Ionosphere, Nature, 691, 1946.

Bilitza, D.: International Reference Ionosphere 2000, Radio Sci., 36, 261-276, 2001.

Bolaji, O., Owolabi, O., Falayi, E., Jimoh, E., Kotoye, A., Odeyemi, O., Rabiu, B., Doherty, P., Yizengaw, E., Yamazaki, Y., Adeniyi, J., Kaka, R., and Onanuga, K.: Observations of equatorial ionization anomaly over Africa and Middle East during a year of deep minimum, Ann. Geophys., 35, 123-132, https://doi.org/10.5194/angeo-35-123-2017, 2017.

Chakraborty, S. K. and Hajra, R.: Electrojet control of ambient ionization near the crest of the equatorial anomaly in the Indian zone, Ann. Geophys., 27, 93-105, https://doi.org/10.5194/angeo27-93-2009, 2009.

Chapman, S.: The equatorial electro-jet as detected from the abnormal electric current distribution about Huancayo, Peru and elsewhere, Arch. Meteor. Geophy. A, 4, 368-390, 1951.

Gouin, P.: Reversal of the magnetic daily variation at Addis Ababa, Nature, 193, 1145-1146, 1962.

Gouin, P. and Mayaud, P. N.: A propos de lexistence possible d'un "contre-electrojet" aux latitudes magnetiques equatoriales, Ann. Geophys., 23, 41-47, 1967.

Hajra, R., Chakraborty, S. K., and Paul, A.: Electro-dynamical control of the ambient ionization near the equatorial anomaly crest in the Indian zone during counter electrojet days, Radio Sci., 44, RS3009, https://doi.org/10.1029/2008RS003904, 2009.

Kane, R. P. and Rastogi, R. G.: Some Characteristics of the Equatorial Electrojet in Ethiopia (East Africa), Indian J. Radio Space, 6, 85-101, 1977.

Kane, R. P. and Trivedi, N. B.: Are the equatorial electrojet and counterelectrojet centered invariably on the dip equator, J. Atmos. Terr. Phys., 44, 301-304, 1982.

Mungufeni, P., Habarulema, J. B., and Jurua, E.: Modeling of Ionospheric Irregularities during Geomagnetically Disturbed Conditions over African Low Latitude Region, Space Weather, 710723, https://doi.org/10.1002/2016SW001446, 2016.

Olwendo, O. J., Yosuke, Y., Pierre, C., Baki, P., Ngwira, C. M., and Mito, C.: A study on the response of the Equatorial Ionization Anomaly over the East Africa sector during the geomagnetic storm of November 13, 2012, Adv. Space Res., 55, 2863-2872, https://doi.org/10.1016/j.asr.2015.03.011, 2015.

Rabiu, A. B., Onwumechili, C. A., Nagarajan, N., and Yumoto, K.: Characteristics of equatorial electrojet over India determined from a thick current shell model, J. Atmos. Sol.-Terr. Phy., 92, 105-115, 2012.

Rastogi, R. G.: Westward Equatorial Electro-jet During Daytime Hours, J. Geophys. Res., 79, 1503-1512, 1974.

Reddy, C. A.: The Equatorial Electro-jet, PAGEOPH, 131, 485508, 1989.

Rodriguez-Zuluaga, J., Radicella, M., S., Nava, B., AmoryMazaudier, C., Mora-Páez, H., and Alazo-Cuartas, K.: Distinct responses of the low-latitude ionosphere to CME and HSSWS: The role of the IMF Bz oscillation frequency, J. Geophys. Res.Space Phys., 121, 11528-11548, 2016.

Rush, C. M. and Richmond, A. D.: The relationship between the structure of the equatorial anomaly and the strength of the equatorial electrojet, J. Atmos. Terr. Phys., 35, 1171-1180,, 1973. 
Rush, C. M., Rush, S. V., Lyons, L. R., and Venkateswaran, S. V.: Equatorial anomaly during a period of declining solar activity, Radio Sci., 4, 829-841, 1969.

Sastri, J. H.: Post-Sunset Behaviour of the Equatorial Anomaly in the Indian Sector, Indian J. Radio Space, 11, 33-37, 1982.

Sastri, J. H.: Equatorial anomaly in F-region - A review, Indian J. Radio Space, 19, 225-240, 1990.

Seemala, G. and Valladares, C.: Statistics of total electron content depletions observed over the South American continent for the year 2008, Radio Sci., 46, RS5019, https://doi.org/10.1029/2011RS004722, 2011.

Sethia, G., Rastogi, R. G., Deshpande, M. R., and Chandra, H.: Equatorial Electrojet Control of the Low Latitude Ionosphere, J. Geomagn. Geoelectr., 32, 207-216, 1980.

Subhadra Devi, P. K. and Unnikrishnan, K.: Study of daytime vertical $\boldsymbol{E} \times \boldsymbol{B}$ drift velocities inferred from ground-based magnetometer observations of $\Delta H$, at low latitudes under geomagnetically disturbed conditions, Adv. Space Res., 53, 752-762, 2014.

Venkatesh, K., P. R., Fagundes, D. S. V. V. D., Prasad, C. M., Denardini, A. J., de Abreu, R. D. J., and Gende, M.: Day-to-day variability of equatorial electro-jet and its role on the day-to-day characteristics of the equatorial ionization anomaly over the Indian and Brazilian sectors, J. Geophys. Res.-Space Phys., 120, 9117-9131, https://doi.org/10.1002/2015JA021307, 2015.
Yizengaw, E., Moldwin, M. B., Mebrahtu, A., Damtie, B., Zesta, E., Valladares, C. E., and Doherty, P.: Comparison of storm time equatorial ionospheric electrodynamics in the African and American sectors, J. Atmos. Sol.-Terr. Phy., 73, 156-163, 2010.

Yizengaw, E., Moldwin, M. B., Zesta, E., Biouele, C. M., Damtie, B., Mebrahtu, A., Rabiu, B., Valladares, C. F., and Stoneback, R.: The longitudinal variability of equatorial electrojet and vertical drift velocity in the African and American sectors, Ann. Geophys., 32, 231-238, https://doi.org/10.5194/angeo-32-231-2014, 2014.

Yue, X., Schreiner, W., Kuo, Y., and Lei, J.: Ionosphere equatorial ionization anomaly observed by GPS radio occultations during 2006-2014, J. Atmos. Sol.-Terr. Phy., 129, 30-40, 2015.

Zhang, M.-L., Wan, W., Liu, L., and Ning, B.: Variability study of the crest-to-trough TEC ratio of the equatorial ionization anomaly around $120^{\circ}$ E longitude, Adv. Space Res., 43, 1762 1769, 2009. 